\title{
Ferrous Sulphate-Induced Black Color Discoloration of Teeth: A Case Report
}

\author{
Kala Bahadur Rawal*, H.N. Girish, Andrew G.J, S. Anusha, Min Bahadur Luhar \\ Department of Pharmacy Practice, Togari Veeramallappa Memorial College of Pharmacy, Ballari, Karnataka, INDIA.
}

Received: 24 April 2020

Accepted: 11 June 2020

*Correspondence to:

Dr. Kala Bahadur Rawal, Department of Pharmacy Practice, TVM College of Pharmacy, Ballari-583103, Karnataka, INDIA.

Email:kbrawal52@gmail.com Copyright: (C) the author(s),publisher and licensee Indian Academy of Pharmacists. This is an open-access article distributed under the terms of the Creative Commons Attribution Non-Commercial License, which permits unrestricted non-commercial use, distribution, and reproduction in any medium, provided the original work is properly cited.

\begin{abstract}
Introduction: Several medications will lead to dental discoloration. Black color teeth discoloration is due to iron ferric salts and more commonly ferric sulfide and the exact mechanism for tooth staining due to iron salt is unknown. Still, this evidence is more common with the liquid iron supplement exposure used for the prevention and management of anemia. Case presentation: A 16-year-old female patient admitted to a female general medicine ward with complaints of black color teeth discoloration for one month, fever insidious in onset for three days, breathlessness and dry cough for three days and loose stool three episodes per day since three days. She was a known case of Chronic Kidney Disease since the age of 18 months and on regular medication. No significant family history was present. On Examination, The patient was having black color teeth discoloration BP-110/70mm of Hg, PR-104bpm and SPO2-98\%). On lab Investigation, her blood test revealed ( $\mathrm{Hb}-6.5 \mathrm{gm} / \mathrm{dl})$ and Scr $5 \mathrm{mg} / \mathrm{dl}$ and S. Urea is $127 \mathrm{mg} / \mathrm{dl}$, Sodium- $131 \mathrm{mEq} / \mathrm{L}$ hence diagnosed as Acute Gastroenteritis with Urinary Tract Infection and CKD major with severe anemia and with mild Right hydroureteronephrosis due to bladder outlet obstruction. Treatment: She was treated with Inj. Ciprofloxacin 400mg IV Twice daily, Inj. Metronidazole 500mg IV Thrice daily, Inj. Ceftriaxone $1 \mathrm{~g}$ IV Twice daily, Tab. Ferrous sulfate + folic acid (IFA) 335+0.5mg PO Twice daily, Tab. Folic Acid $5 \mathrm{mg}$ PO Once daily, Tab. Calcium Carbonate + D3 500mg PO Once daily, Tab. Sodium bicarbonate 200mg PO Thrice daily, Syrup Dextromethorphan + Chlorpheniramine + Phenylephrine 10ml Thrice daily. Conclusion: The patient was in the long run (18 months) therapy of iron supplement. The teeth discoloration was developed due to the chronic toxicity of iron supplement (Ferrous sulfate). The iron-rich diet was recommended for the patient and the sulfate salt of iron changed to fumarate salt.
\end{abstract}

Key words: Anemia, Iron, Staining, Adverse drug reactions, Sulfate salts, Drug-induced disorders.

\section{INTRODUCTION}

When the drugs are used to cure the illnesses and are used in the normal therapeutic doses but leading to the undesired and noxious effects, then the condition is known as adverse drug reactions (ADRs). ${ }^{[1-3]}$ Drug-induced disorders are the adverse drug reactions of the drugs. Any form of medication can be associated with various adverse drug reactions and challenge the safety of drug. ${ }^{[4,5]}$ The magnitude of the adverse effect may vary from a minor effect to even the life-threatening condition. ${ }^{[6,7]}$ Anemia due to Chronic Kidney Disease (CKD) is the most common problem in medical and an iron supplement is one of the crucial drugs for the management of anemia. The iron supplements used in the treatment of anemia may lead to the ADRs, Dental discoloration is among them. The black color teeth discoloration (staining) is due to the ferrous salts (iron salts) by interaction with the enamel of dentine but the incidence is high with ferric sulfide salts (sulfide salts of iron). The exact mechanism for tooth staining due to iron salt is unknown but this evidence is more common with the oral liquid iron supplement than other formulations. ${ }^{[8-10]}$

\section{MATERIALS AND METHODS}

The case and caretakers were interviewed for obtaining information after their consent. The data in the patient profile forms and laboratory investigation reports were assessed. The causality assessment was done by the WHO Scale, Naranjo's scale. Oral informed consent was obtained from patients and representative(s). The case study was done ethically according to the declaration of Helsinki by maintaining the subject confidentiality.

\section{Case presentation}

A 16 year old female patient admitted to a female general medicine ward with complaints of black color teeth discoloration for one month, fever insidious in onset for three days, breathlessness and dry cough for three days and loose stool. She was known case of CKD since the age of 18 months and on regular medication. No, any significant family history was present and no habits of tea, coffee, tobacco smoking and chewing, chewing of betel morsel (piper betel, pan).

\section{On Examination}

The patient is having black color teeth discoloration BP-110/70mm of $\mathrm{Hg}, \mathrm{PR}-104 \mathrm{bpm}$ and $\mathrm{SPO}_{2}-98 \%$ ). Causality Assessment World Health Organization (WHO) causality assessment scale, Naranjo's scale and Karsch and Lasagna Causality assessment scale were used to evaluate the causal relationship between the drug and reaction. The following score was obtained after applying the above scales for observed suspected ADR (Table 1). Re-challenging was not done as it is not required as per WHO-UMC for probable drugs. On analysis, the reaction was Bizarre type (Type-B) with a moderate severity of level 4 (a). The reaction can be probably prevented. 
Table 1: Causality assessment scores for suspected ADR.

\begin{tabular}{|l|l|l|}
\hline Scales & Score & Assessment \\
\hline WHO-UMC & 6 & Probable \\
\hline Naranjo's & 5 & Probable \\
\hline
\end{tabular}
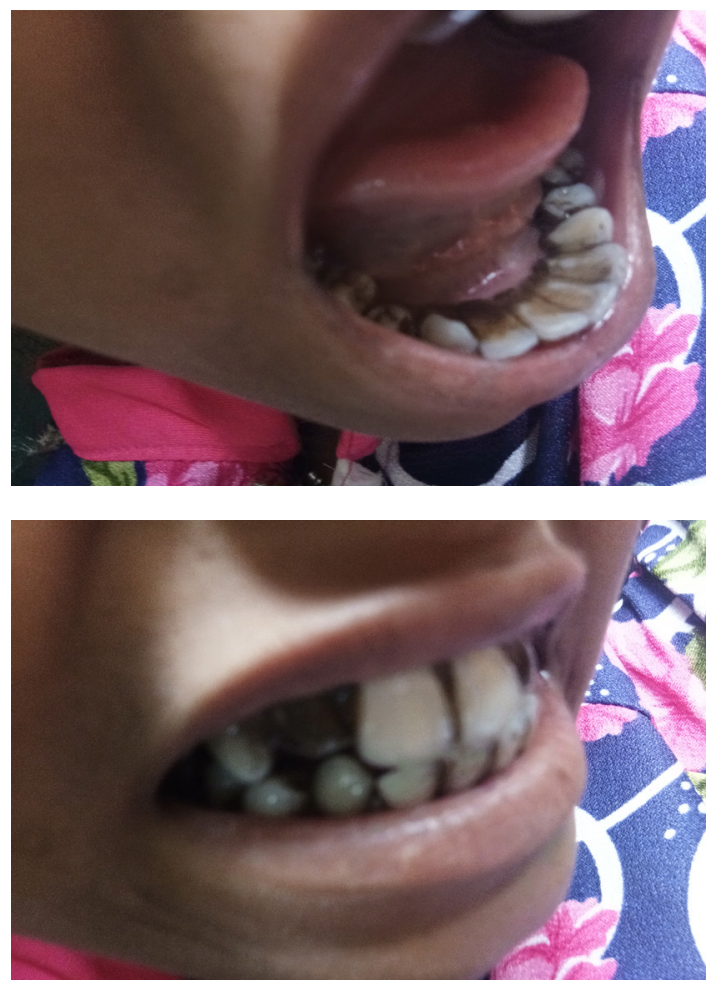

Figures 1 and 2: Black discoloration of teeth due to ferrous sulphate.

\section{On Lab Investigation}

Her blood test revealed $\mathrm{Hb}(6.5 \mathrm{gm} \%) \mathrm{RBC}\left(2.27\right.$ million cells $\left./ \mathrm{mm}^{3}\right)$, Scr. $5 \mathrm{mg} / \mathrm{dl}$ and S. Urea is $127 \mathrm{mg} / \mathrm{dl}, \mathrm{Na}-131 \mathrm{mEq} / \mathrm{L}$ hence diagnosed as Acute Gastroenteritis, Urinary Tract Infection and CKD major with severe anemia and with mild Right hydroureteronephrosis due to bladder outlet obstruction.

\section{Treatment}

She was treated with Inj. Ciprofloxacin 400mg IV twice daily, Inj. Metronidazole 500mg IV thrice daily, Inj. Ceftriaxone $1 \mathrm{~g}$ IV twice daily, Tab. Ferrous sulfate + folic acid 335+0.5mg PO twice daily, Tab. Folic Acid $5 \mathrm{mg}$ PO once daily, Tab. Calcium Carbonate + D3 500mg PO once daily, Tab. Sodium bicarbonate 200mg PO thrice daily, Syrup Dextromethorphan + Chlorpheniramine + Phenylephrine (cough syrup) $10 \mathrm{ml}$ thrice daily.

\section{DISCUSSION}

This case is suspected of ADR due to ferrous sulfate by using WHO and Naranjo's causality assessment scales. The patients were on long run (18 months) therapy of iron supplement. This was due to the chronic toxicity of iron supplement (Ferrous sulfate). ${ }^{[7]}$ Extrinsic black color discoloration of teeth due to liquid oral preparation ferrous salts more common, among ferrous higher incidence with sulfide salts in a ferric form which forms interact with the enamel of teeth and resulting in black color staining of teeth. ${ }^{[8-10]}$
Exposure of ferrous sulfate increases due uncoating of the sugar-coated tablet of ferrous sulfate. ${ }^{[11]}$ This patient was Physically disabled and she not having normal physical growth as per the age required so cannot perform physical activities normally so having the problem in swallowing leading to uncoating of tablet sugar-coated IFA due to the increase in the transit time of the drug in mouth and more interaction of active ingredient and teeth leading to the ADR.

\section{CONCLUSION}

Even though the patient is consuming ferrous sulfate sugar-coated tablets, whose coating was broken due to keeping for a long period in the mouth due to swallowing problems. The iron-rich diet was recommended for patients and the high dose of sulfate salts of iron changed to a lower dose of fumarate salts of iron have less incidence of teeth discoloration than sulfate salts and even ferrous fumarate have less dose compared to ferrous sulfate.

\section{ACKNOWLEDGEMENT}

We authors want to thank Dr. Anwar MI, Unit Chief of Nephrology for his clinical guidance during the ward rounds and follow up of the case. We would also like to thank Prof. Manjunath V. Jali and Dr. RLN Murthy for their support and encouragement for this work.

\section{CONFLICT OF INTEREST}

Authors declare no conflict of interest.

\section{Funding}

Nil.

\section{ABBREVIATIONS}

IFA: Ion Folic Acid; USG: Ultrasonography; CKD: Chronic Kidney Disease; IV: Intravenous; UTI: Urinary Tract Infection; GE: Gastroenteritis; BP: Blood Pressure; PR: Pulse Rate; Hb: Hemoglobin; Scr: Serum Creatinine; S. Urea: Serum Urea; RBC: Red Blood Cells.

\section{REFERENCES}

1. Anusha R, Chand S, Lal V, et al. Isoniazid-induced liver injury: A case series and review. Journal of Pharmacy Practice and Community Medicine. 2018;4(2):128-30.

2. Chand S, Bhandari R, Girish HN, et al. Isoniazid Induced Psychosis. Journal of Global Pharma Technology. 2019;11(5):11-4.

3. Voora L, Shastry CS, Bhandari R, et al. Phenytoin-Induced Erythroderma. J Young Pharm. 2019;11(3):320-1.

4. Voora L, Sah SK, Bhandari R, et al. Doctor of Pharmacy: Boon for Healthcare System. Drug Invention Today. 2020;14(1):153-8.

5. Rawal KB, Chand S, Luhar MB, et al. A Comparative Study on Relative Safety and Efficacy of Chlorpromazine and Risperidone. International Journal of Research in Pharmaceutical Sciences. 2020;11(02):1539-44.

6. Rachana J, Shastry CS, Mateti UV, et al. Incidence and associated factors of adverse drug reactions in the general medicine department of a tertiary care teaching hospital. International Journal of Pharmaceutical Research. 2019;11(3):177-84.

7. Chand S, Bhandari R, Lal V. Prednisolone Induced Cushing's syndrome in Seropositive Inflammatory Arthritis. Indo American Journal of Pharmaceutical Research. 2018;8(04):595-7.

8. Amit T, Srivastava BK, Ramesh N, Pradeep T, Ravishankar TL. An investigation into black tooth stain among school children in Chakkar Ka Milak of Moradabad city, India. J Oral Health Comm Dent. 2009;3(2):34-7.

9. Andre G, Carlos AC, Sandra MM, Ernesto YM, Mariliane C, et al. Prevalence of black tooth stains and dental caries in Brazilian schoolchildren. Braz Dent J. 2003;14(3):157-61.

10. Alvarez JA, Rezende KM, Marocho SM, Alves FB, Celiberti P, Ciamponi AL. Dental fluorosis: exposure, prevention and management. Med Oral Patol Oral Cir Bucal. 2009;14:E103-7.

11. Claire OB. httpps;//www.activeiron.com/2017/07/04iron-supplement-tooth -discoloration-staining-protect-your-smile/

Cite this article as: Rawal KB*, Girish HN, Andrew GJ, Anusha S, Luhar MB. Ferrous Sulphate-Induced Black Color Discoloration of

Teeth: A Case Report. J Pharm Pract Community Med. 2020;6(2):29-30. 